\title{
Size Effect in Flexure of Prestressed Concrete Beams Failing by Compression Softening
}

\author{
Jan Vorel ${ }^{1}$; Mahendra Gattu²; and Zdeněk P. Bažant, Dist.M.ASCE ${ }^{3}$
}

\begin{abstract}
The typical cause of flexural failure of prestressed beams is compression crushing of concrete, which is a progressive softening damage. Therefore, according to the amply validated theory of deterministic (or energetic) size effect in quasi-brittle materials, a size effect must be expected. A commercial finite-element code, ATENA, with embedded constitutive equations for softening damage and a localization limiter in the form of the crack band model, is calibrated by the existing data on the load-deflection curves and failure modes of prestressed beams of one size. Then this code is applied to beams scaled up and down by factors of 4 and $1 / 2$. It is found that the size effect indeed takes place. Within the size range of beam depths of approximately $152-1,220 \mathrm{~mm}$, the size effect represents a nominal strength reduction of about $30 \%$ to $35 \%$. In the interest of design economy and efficiency, a size effect correction factor could be introduced easily into the current code design equation. However, this is not really necessary for safety since the safety margin required by the code is exceeded for the normal practical size range if the hidden safety margins are taken into account. The mildness of the size effect in the normal size range is explained by the fact that the compression softening zone occupies a large portion of the beam and that, at peak load, the normal stress profiles across the softening zone exhibit only a minor stress reduction below the strength limit. Fitting the type 2 size effect law to the data can provide a simple extrapolation to much deeper beams, for which a stronger size effect is expected. But the extrapolation has some degree of uncertainty because of higher scatter of the test data used for calibrations. DOI: 10.1061/(ASCE)ST.1943-541X.0000983. (C) 2014 American Society of Civil Engineers.
\end{abstract}

Author keywords: Concrete; Scaling of structural strength; Prestressed concrete design; Compression failure; Fracture mechanics; Damage mechanics; Analysis and computation.

\section{Introduction}

If a building material obeys elasticity or plasticity, geometrically similar structures of different sizes fail at the same stress values at homologous points (Bažant and Planas 1997; Bažant 2005). In other words, in plastic limit analysis, the material strength criterion suffices to predict failure, and there is no size effect.

But if a material characteristic length, or any quantity with the dimension of surface energy, is a part of the material failure criterion, then the strength (the stress value at maximum load) exhibits a deterministic (or energetic) size effect-i.e., decreases with increasing structure size, $D$ (Bažant 2005, 1984; Bažant and Planas 1997). The size effect is a salient universal property of all brittle heterogeneous materials, termed quasi-brittle. Of those, concrete is the archetypical example. The size effect has been experimentally demonstrated and theoretically modeled for most brittle types of failure of plain and reinforced concrete structures, which are characterized by lack of a yield plateau. They include

\footnotetext{
${ }^{1}$ Assistant Professor, Dept. of Mechanics, Faculty of Civil Engineering, Czech Technical Univ. in Prague, Thákurova 7, 16629 Praha 6, Czech Republic; and Visiting Scholar, Northwestern Univ., 2145 Sheridan Rd., Evanston, IL 60208. E-mail: jan.vorel@fsv.cvut.cz

${ }^{2}$ Graduate Research Assistant, Northwestern Univ., 2145 Sheridan Rd., Evanston, IL 60208.

${ }^{3}$ McCormick Institute Professor and W. P. Murphy Professor of Civil and Mechanical Engineering and Materials Science, Northwestern Univ., 2145 Sheridan Rd., CEE/A135, Evanston, IL 60208 (corresponding author).E-mail: z-bazant@northwestern.edu

Note. This manuscript was submitted on March 11, 2013; approved on October 25, 2013; published online on May 12, 2014. Discussion period open until October 12, 2014; separate discussions must be submitted for individual papers. This paper is part of the Journal of Structural Engineering, (c) ASCE, ISSN 0733-9445/04014068(8)/\$25.00.
}

shear and torsional failures of beams, punching failures of slabs, pullout of anchors and studs, and bending or shear of plain concrete beams, slabs, and walls.

Unlike flexure of unprestressed reinforced concrete beams, which can be designed to fail due to steel reinforcement yielding, the flexural failure of prestressed beams is brittle. This is evidenced by the absence of a yield plateau and by postpeak softening that begins right after the maximum load. Because of prestress, brittle flexural behavior cannot be avoided by using a steel ratio below a balanced steel ratio. Although flexural failure of prestressed beams can be caused by yielding of the prestressing steel, the usual cause is compression crushing of concrete. The crushing causes a size effect.

Unfortunately, the experimental evidence does not include the size effect. Although laboratory tests of flexural failure of prestressed concrete beams were carried out long ago (Janney et al. 1956; Billet 1953; Feldman 1954; Warwaruk 1957; Tan and Mansur 1992; Raju et al. 1973), it appears that no test series with a significant size range has ever been carried out, doubtless because the plastic limit analysis was the only theory of structural strength in the $1950 \mathrm{~s}$, when these tests were made. So it is impossible to decide the question of size effect purely on the basis of the existing experimental data.

Nowadays, it is nevertheless possible to obtain realistic predictions of the failure of quasi-brittle structures using a finite-element code with a realistic triaxial constitutive model for softening damage and a localization limiter, provided that the code is adequately calibrated by experiments. Suitable for this purpose is the commercial code ATENA (Červenka and Jendele 2008), which uses the crack band model as the localization limiter (Bažant and Planas 1997) and offers the choice of two embedded constitutive models for softening damage - a tensorial plastic damage 
model and a microplane model called M4. Another suitable code is the Object-Oriented Finite Element Solver code (OOFEM; Patzák and Bittnar 2001), which also includes the M4 model, as well as the nonlocal model serving as the localization limiter.

Therefore, to settle the question of size effect in flexural failure of prestressed beams, the finite-element code first is calibrated and validated by fitting the aforementioned test results. Then the calibrated code is run for geometrically scaled beams of significantly different sizes to determine the size effect.

\section{Available Test Data Used for Calibration}

Extensive flexural tests of prestressed concrete beams were carried out in the early 1950s at the Portland Cement Association in Skokie, Illinois, by Janney et al. (1956), and at the University of Illinois at Urbana-Champaign by Billet (1953), Feldman (1954), and Warwaruk (1957). The experiments in the subsequent years were focused on bond characteristics, influence of various levels of prestressing, types of reinforcement, behavior under fatigue loading, prestressed and fiber-reinforced concretes, etc. Flexural tests of beams failing by compression crushing were made by Billet (1953), Warwaruk (1957), Tan and Mansur (1992), and Raju et al. (1973).

Billet (1953) tested 27 rectangular beams with the cross-section depth of $305 \mathrm{~mm}$, width of $152 \mathrm{~mm}$, and span of 2,743 $\mathrm{mm}$. The loads were applied symmetrically at $1 / 3$ of the span so that the middle third of the span would be in pure flexure. The prestress was provided by patented, cold-drawn, and stress-relieved or galvanized high-strength steel wires. Adequate provisions against shear failures were made in practically all the beams. None of the beams had compression reinforcement.

The beams can be grouped into four major series in which the prestress, percentage of steel, concrete strength, and type of reinforcement have been varied. Of these 27 beams, beams labeled B-7, B-8, B-13, B-25, B-26, and B-27 were overreinforced and failed in compression involving development of $\mathrm{V}$-shaped cracks, as shown in Billet (1953).

\section{Nominal Strength as an Indicator of Size Effect}

In unprestressed reinforced concrete beams, the design code (ACI Committee 318 2008) requires the steel ratio to be less than $75 \%$ of the balanced steel ratio, in order to ensure the beam to fail by the yielding of steel rather than by the crushing of concrete. Therefore, in such beams, termed underreinforced, there can be no size deterministic effect; i.e., the nominal strength $\sigma_{N}$ is independent of beam depth $h$.
By contrast, prestressed beams behave like overreinforced beams. They typically fail by compression crushing of concrete while the stress in steel is still below the yield limit. The crushing is described properly by damage mechanics, in which the stress-strain relation exhibits strain softening. But the concept of strain softening makes sense only if the localization of damage strain is limited by a certain material characteristic length, $l_{c}$. This length must cause the flexural failure of prestressed concrete beams to exhibit a size effect. The only questions are: How strong is the size effect? What is the transitional size below which the size effect is negligible?

In the standard design procedure [ACI Committee 318 2008; International Federation for Structural Concrete (fib) 2010], the actual curvilinear distribution of the compressive stress at failure is replaced by an equivalent rectangular stress block with a compression resultant of in the same magnitude and the same location (Fig. 1). The nominal strength $\sigma_{N}$ is defined most conveniently as the stress in this block. Based on the conditions of equilibrium of horizontal forces and moments

$$
\sigma_{N}=\frac{C}{a b}
$$

where

$$
a=2\left(d_{p}-\frac{M_{u}}{T}\right), \quad T=A_{p s} f_{p s}
$$

Here, $d_{p}=$ depth from the top face to the centroid of reinforcement; $a=$ depth of the rectangular stress block; $b$ is its width; $M_{u}=$ maximum (or ultimate) bending moment; $T=$ total tensile force in all prestressing steel; $A_{p s}=$ cross-section area of all prestressing steel; and $f_{p s}=$ stress in the prestressing steel (Fig. 1). The design code (ACI Committee 318 2008) also gives the empirical expression $a=\beta_{1} c$, where $\beta_{1}=0.85-0.05\left[\left(f_{c}^{\prime} / 1000 \mathrm{psi}\right)-4\right]$ if $0.65<\beta_{1}<0.85$, while $\beta_{1}=0.85$ if $f_{c}^{\prime} \leq 4,000 \mathrm{psi}$ and $\beta_{1}=$ 0.65 if $f_{c}^{\prime} \geq 8,000$ psi (Nilson 1987). The value of $\sigma_{N}$ at the ultimate moment $M=M_{u}$ is specified in the code as $0.85 f_{c}^{\prime}$, where $f_{c}^{\prime}$ stands for the compression strength. Since the code specifies $\sigma_{N}$ at failure to be a constant, regardless of the beam size or depth $d$, there is no size effect according to the design code.

A more accurate way of determining coefficient $\beta_{1}$ and $M_{u}$ is to use the so-called strain compatibility analysis (Nilson 1987; Nawy 2006). But this analysis depends on the simplifying hypothesis of planar cross sections, which loses accuracy once the softening compression failure begins to propagate.

Any dependence of $\sigma_{N}$ on the beam size represents a size effect. To check for this size effect, Eqs. (1) and (2) will be used to determine $\sigma_{N}$ from the measured or numerically calculated values of $T$ and $M_{u}$.

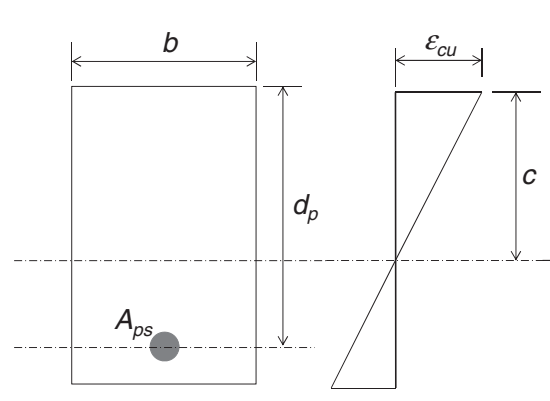

(a) (b)

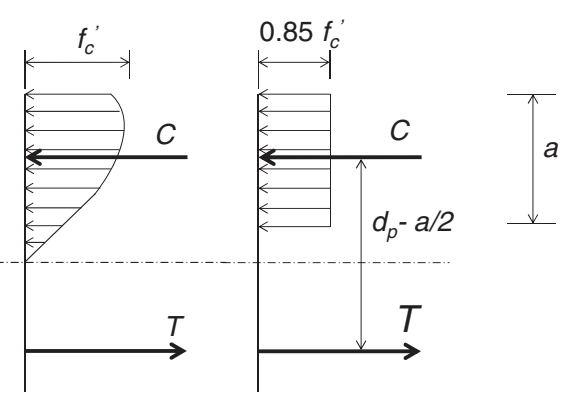

(c) (d)

Fig. 1. Stress and strain distribution at failure load: (a) cross section; (b) strains; (c) actual stress distribution; (d) equivalent rectangular stress distribution 


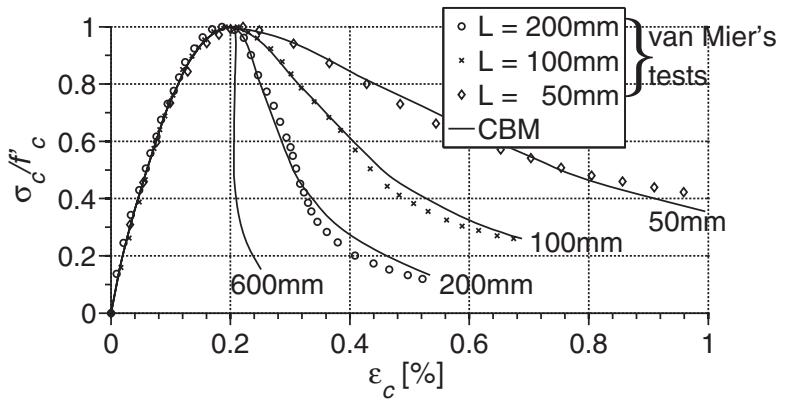

Fig. 2. Van Mier's compression tests of square prisms of various lengths (L) and their fit with a uniaxial crack band model (CBM) by Bažant and Cedolin (1991); note that the predicted curve for $600 \mathrm{~mm}$ could not have been tested in the same way even in a perfectly stiff machine because it exhibits snapback

\section{Localization in Compression: Crack Band Model and van Mier's Experiments}

During the 1960s, it was discovered that prismatic concrete specimens that were not too long (i.e., with length-to-width ratio <5) and that were subjected to compression in a sufficiently stiff loading frame do not fail abruptly at the peak load but exhibit gradual postpeak strain softening. In 1976, it was demonstrated by energy stability analysis (Bažant 1984) that the concept of strain softening makes sense only if it is defined as the property of a band (later named the crack band) of a certain finite width $w_{c}=n d_{a}$ that is a material property determined by the maximum size of material inhomogeneities, $d_{a}$ (with $n \geq 1$ ). It was shown that, in an infinitely stiff loading frame, the critical postpeak softening modulus under uniaxial compression varies as $\left|E_{t}\right|=E\left(L / w_{c}-1\right)$, where $E=$ Young's modulus. This implies that the longer the specimen, the steeper the softening ( $L=$ specimen length); see Fig. 2. In other words, the smaller specimens are more ductile and the larger ones are more brittle.

The effect of specimen length $L$ on the steepness of postpeak compression softening was demonstrated experimentally in 1984 by van Mier's tests of square prisms of different lengths loaded in uniaxial compression (van Mier 1984). Bažant and Cedolin (1991) showed that van Mier's results can be matched closely when the postpeak softening is assumed to localize into a band of fixed width $w_{c}$ (see Fig. 2 of this paper, as well as a similar comparison in Fig. 13.11 on p. 855 of Bažant and Cedolin 1991).

The effect of compression strain softening on the momentrotation diagrams of hinges that govern the stability and failure of unprestressed reinforced concrete beams was analyzed in 1976 in Bažant (1984). Inspired by van Mier's tests, Hillerborg (1990) proposed a particularly simple model for the softening hinge in flexure of a reinforced beam [see also section 10.5.12, p. 380 in Bažant and Planas (1997)]. He assumes that the cross sections remain planar and, as shown in Fig. 3, he imagined the hinge to consist of a tensile stress-free crack extending up to the neutral axis and a rectangular compressed zone of width $h=\eta c$, where $c$ is the distance from the compressed face to the neutral axis and $\eta$ is an empirical constant approximately equal to 0.8 . The essential property is that the postpeak uniaxial stress-strain relation is scaled such that it terminates at zero stress with size-dependent strain $\varepsilon_{0}=w_{c} / h$. This causes the resulting moment-curvature diagram to depend on the dimensionless size, defined as

$$
D^{*}=\frac{D}{l_{c}}, \quad l_{c}=w_{c} \frac{E}{2 f_{c}^{\prime}}
$$

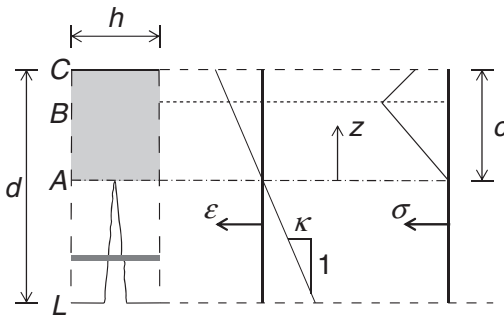

(a) (b)

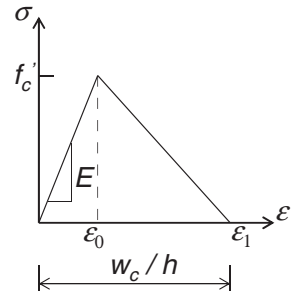

Fig. 3. Hillerborg model: (a) damage localization zone in beam cross section; (b) constitutive law for compression

where $l_{c}=$ characteristic length of concrete. The stress profile can be computed as a function of the position $c$ of neutral axis and the beam curvature $\kappa$, whereas $c$ can be computed from the force equilibrium equation for any given $\kappa$. The bending moment may then be calculated from the moment-equilibrium equation. Thus, the full moment-curvature diagram is obtained.

Hillerborg's formulation predicts that, for increasing crosssection depth (or size), the plateau of the maximum bending moment shortens; i.e., the brittleness increases. These phenomena affect the postpeak load-deflection diagrams of statically indeterminate structures and their safety margins (Bažant 2003a, b). The design codes (ACI Committee 318 2008; fib 2010) exhibit none of these effects.

\section{Compressive Shear Bands Consisting of Splitting Cracks}

In brittle and quasi-brittle materials, compression failure begins by the formation of axial-splitting cracks (Bažant and Xiang 1994, 1997). However, the axial-splitting cracks do not change the macroscopic continuum stress state along the cracks caused by uniaxial compression. Consequently, there is no energy release. Hence, by themselves, they cannot be the mechanism of compression failure and cannot control the failure load.

The axial-splitting cracks can only be the mechanism that triggers the macroscopic compression failure (Bažant and Xiang 1994). The principal mechanism of compression failure of concrete bars and beams is sideways propagation of a band of parallel axialsplitting cracks, in a direction that is either orthogonal or (more likely) inclined with respect to the direction of compression; see Fig. 4, which shows several alternative geometries of a crack band,

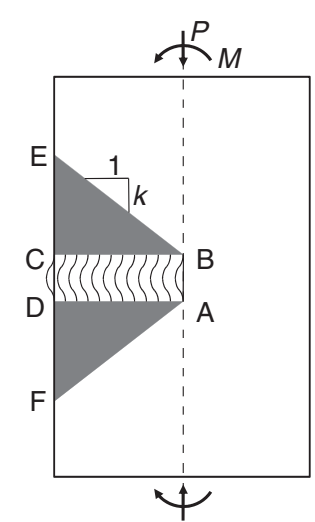

(a)

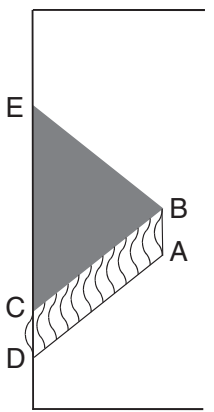

(b)

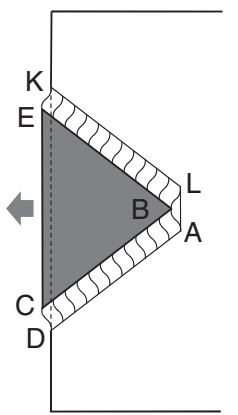

(c)
Fig. 4. Feasible splitting cracks $(\mathrm{BCE}, \mathrm{ADF}=$ stress relief zone; $\mathrm{ABCD}, \mathrm{BEKL}=$ crack band; and $k=$ slope of stress diffusion line) 
which lead to equivalent results. The local buckling of the material between parallel splitting cracks leads to compression crushing (or compression-shear crushing). This mechanism was investigated within the context of finite strain theory in Bažant (1967).

A significant size effect was theoretically derived and experimentally demonstrated for the compression buckling failure of reduced-scale slender microreinforced concrete columns under eccentric axial loads (Bažant and Kwon 1994). Their nominal strength was shown to decrease strongly with an increasing column size $d$, and approach an asymptote of slope $-2 / 5$ for large sizes in a doubly logarithmic plot. Partial similarity with these columns was one of the motivations for the present study. The limited ductility of inelastic hinges in reinforced concrete beams and frames, which is always associated with size effect, was discussed in Barnard (1965) and Barnard and Johnson (1965) and analyzed in detail in Bažant (2003a, b).

\section{Finite-Element Simulations}

The beam is loaded at four points and, assuming symmetric behavior, only half of the beam is modeled, as shown in Fig. 5. The reinforcement bars are modeled as one-dimensional truss elements. The concrete is discretized in three dimensions using eight-node hexahedral elements. For the three smallest sizes of beams, the element size is kept constant at $25 \mathrm{~mm}$, and for the largest beams, the size is doubled to decrease the computational cost. The element size increase is made possible by using the crack band model.

Beams from the aforementioned data set were selected and modeled with finite-element software ATENA 3D (Červenka and Jendele 2008), considering the same geometry, loading, initial prestress, and material properties (see Table 1 for the beam labels). Although the M4 model is available with ATENA, the simpler constitutive model (CC3DNonLinCementitious2) embedded in ATENA was deemed to be sufficient because the loading path is relatively simple (e.g., compared to impact loading), because the concrete confinement is not high, and because unloading plays no role in the process. CC3DNonLinCementitious 2 is the fracture-plastic model combining constitutive models for the tensile

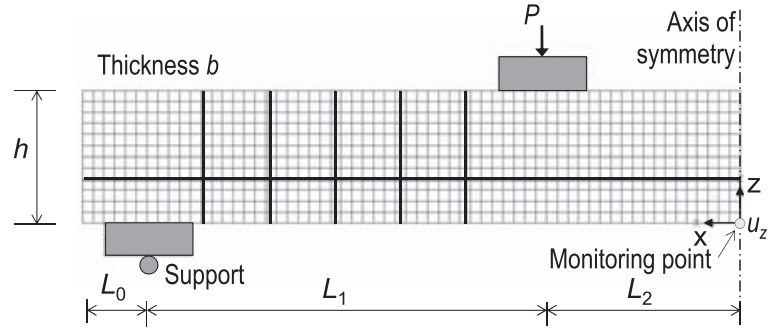

Fig. 5. ATENA finite-element model for four point bending simulation

Table 1. Test Parameters

\begin{tabular}{lccccc}
\hline Beam label & $f_{c}^{\prime}(\mathrm{MPa})$ & $d_{p}(\mathrm{~mm})$ & $A_{p s}\left(\mathrm{~mm}^{2}\right)$ & $f_{s e}(\mathrm{MPa})$ & $E(\mathrm{MPa})$ \\
\hline B-7 & 40.8 & 205 & 301 & 777 & 34,007 \\
B-8 & 28.3 & 207 & 301 & 778 & 26,367 \\
B-13 & 29.7 & 204 & 208 & 146 & 15,381 \\
B-25 & 22.6 & 203 & 201 & 790 & 16,414 \\
B-26 & 12.5 & 236 & 161 & 803 & 9,000 \\
B-27 & 31.7 & 211 & 301 & 814 & 16,450 \\
\hline
\end{tabular}

Note: $f_{s e}$ is the steel stress due to effective prestress force after deduction of all losses. (fracturing) and compressive (plastic) behavior. The fracture model is based on the classical orthotropic smeared crack formulation and crack band model. It employs Rankine failure criteria and exponential softening, and it can be used as a rotated or fixed crack model. The hardening/softening plasticity model is based on the MenétreyWillam failure surface. The return-mapping algorithm is used for the integration of constitutive equations. The model can be used to simulate concrete cracking, crushing under high confinement, and crack closure due to crushing in other material directions; for more, see Červenka and Jendele (2008).

Application of the prestress is simulated first. Then the loads are applied symmetrically at each third of the span through steel blocks placed on top of the beam. The loading is displacement controlled. The known material parameters of concrete (compressive strength $f_{c}^{\prime}$ and elastic modulus $E$ ) are used directly, as presented by Billet (1953) separately for each beam (Table 1). The unknown material parameters (tensile strength $f_{t}^{\prime}$, Poisson's ratio $\nu$, fracture energy $G_{f}$, and the end point $w_{d}$ of the strain-softening curve in compression) of the concrete material model are adjusted to match the measured load-deflection curve and reproduce the observed compression crushing mode of failure (Table 2). The reinforcing steel is assumed to be elastoplastic, and its material parameters are adopted from Billet (1953) as well.

The simulations are found to capture the failure mechanism both qualitatively and quantitatively. The load-deflection curves obtained from the simulations agree well with the experiments [Figs. 6(a-f)]. For an overreinforced beam, the loading to failure may be divided into three distinct stages. In the first stage, the load deflection is linear and the beam behaves elastically. In the second stage, the concrete at the bottom of the beam is decompressed and starts cracking. This causes a reduction in the stiffness of the beam and a corresponding reduction in the slope of the load-deflection curve. In the third stage, the concrete in compression at the top of the beam reaches its peak stress and begins softening. The neutral axis starts moving downward to accommodate this softening, and the beam fails by compressive crushing. To demonstrate the failure mechanism, the corresponding crack patterns after failure are depicted in Fig. 7.

Fig. 8 shows the computed vertical profiles of longitudinal stress $\sigma_{x x}$ at midspan. Subsequent profiles are plotted for the prestressing stage, decompression stage, tensile cracking stage, and peak load state with compressive softening. The neutral axis is seen to move down during the loading, which agrees with the beam-type analysis of prestressed beams (by contrast, for unprestressed beams, the neutral axis moves up).

Table 3 and Fig. 9 give a numerical comparison of the ultimate (maximum) loads from the experiment and from finite-element simulations. Also given are the results of the strain compatibility analysis, which is a beam-type analysis with the assumption of plane cross sections (Nilson 1987; Nawy 2006). The values of $f_{p s}$ obtained from experiment and finite-element simulations agree reasonably well except for beams B-8 and B-13. The maximum load, $P_{\text {ult }}$, differs from the experimental value by less than $4 \%$

Table 2. Material Parameters Utilized for the Simulation

\begin{tabular}{lcccc}
\hline Beam & $f_{t}^{\prime}(\mathrm{MPa})$ & $\nu(-)$ & $G_{f}(\mathrm{~N} / \mathrm{m})$ & $w_{d}(\mathrm{~mm})$ \\
\hline B-7 & 0.8 & 0.2 & 62.4 & 0.5 \\
B-8 & 2.0 & 0.2 & 62.4 & 0.5 \\
B-13 & 2.0 & 0.2 & 62.4 & 0.5 \\
B-25 & 1.4 & 0.2 & 62.4 & 0.5 \\
B-26 & 0.8 & 0.2 & 62.4 & 0.5 \\
B-27 & 1.4 & 0.2 & 62.4 & 0.5 \\
\hline
\end{tabular}




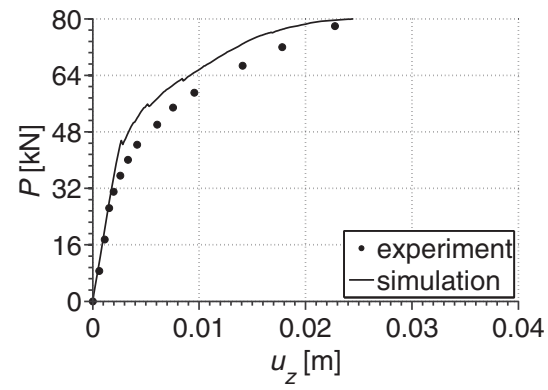

(a)

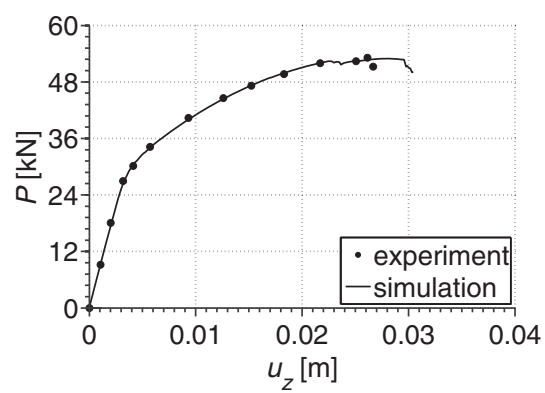

(d)

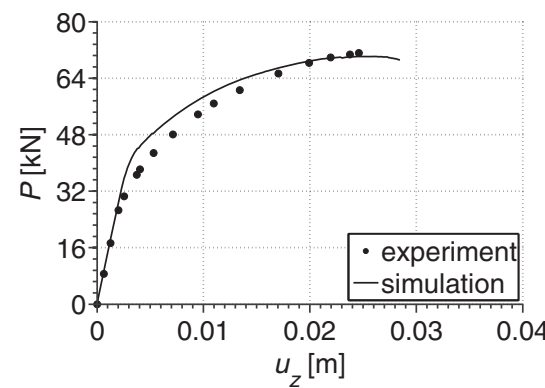

(b)

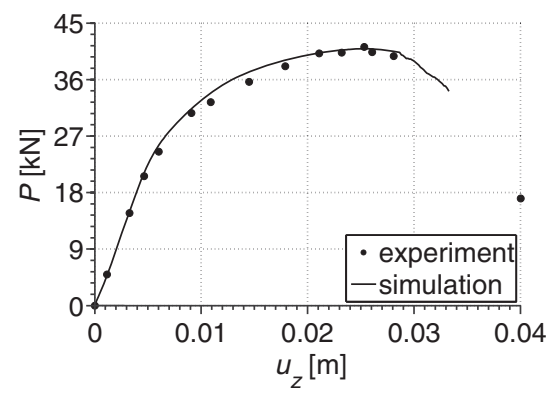

(e)

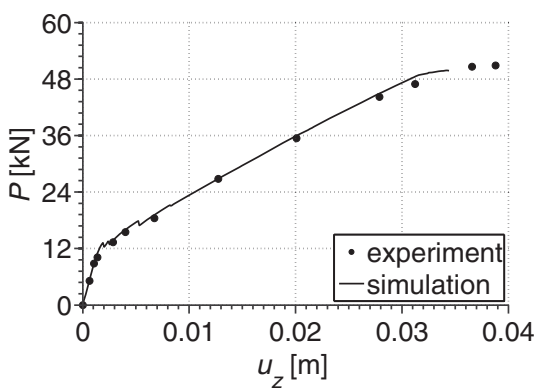

(c)

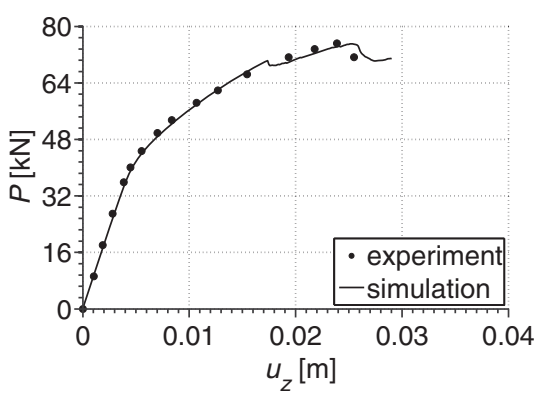

(f)

Fig. 6. Load-deflection curves for beams: (a) B-7; (b) B-8; (c) B-13; (d) B-25; (e) B-26; (f) B-27

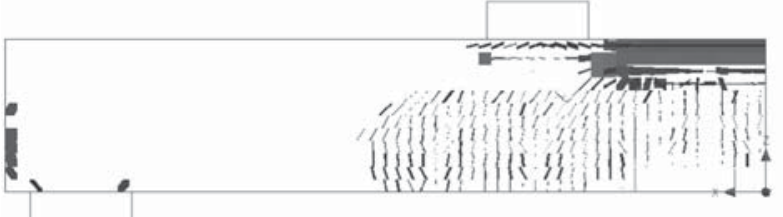

(a)

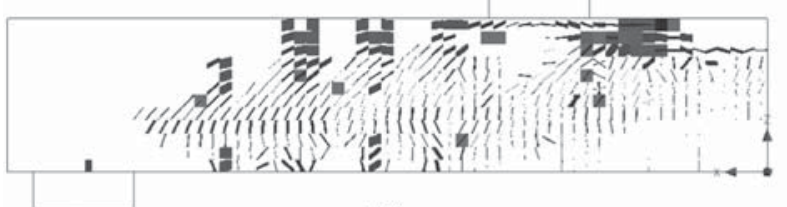

(c)

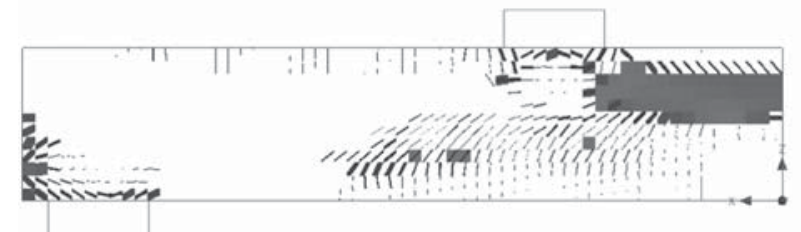

(e)

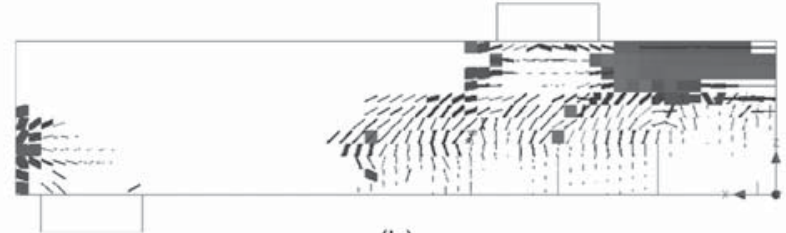

(b)

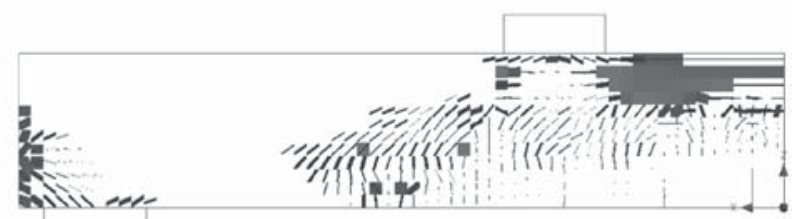

(d)

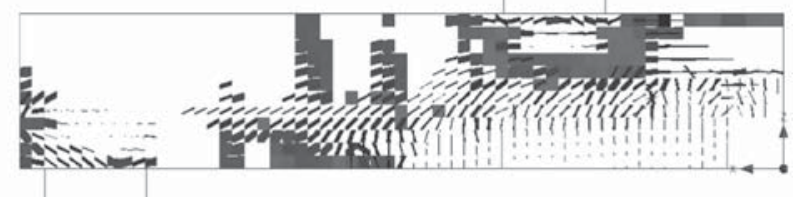

(f)

Fig. 7. Computed crack patterns at incipient failure, as indicated stability loss of three-dimensional finite element simulation with software ATENA 4.3.1 (run under load-point displacement control). The line thickness is proportional to the crack width and the crack orientation is a planar projection from three dimensions. The dark zones on top the beam are vertical compression splitting cracks parallel to the side face of beam: (a) B-7; (b) B-8; (c) B-13; (d) B-25; (e) B-26; (f) B-27

(according to beam-type strain compatibility analysis, this difference is negligible for beams B-7, B-13, and B-27, less than $14 \%$ for beams B-25 and B-26, and $23 \%$ for beam B-8).

Note that the control modeling and calculations were done by means of the damage-plastic model for concrete, as described in detail in Grassl and Jirásek (2006) and implemented in OOFEM. These results matched well the results obtained by the ATENA software.

\section{Size Effect on Nominal Strength of Geometrically Scaled Beams}

The finite-element models of Beams B-8 and B-26 (Billet 1953) are scaled geometrically up by a factor of 4 and down by a factor of 0.5 , while keeping the width $b$ constant. This creates two sets of four beams, each set with the size ratio of $1: 2: 4: 8$. The material parameters and the stress in the prestressing steel are kept the same. 


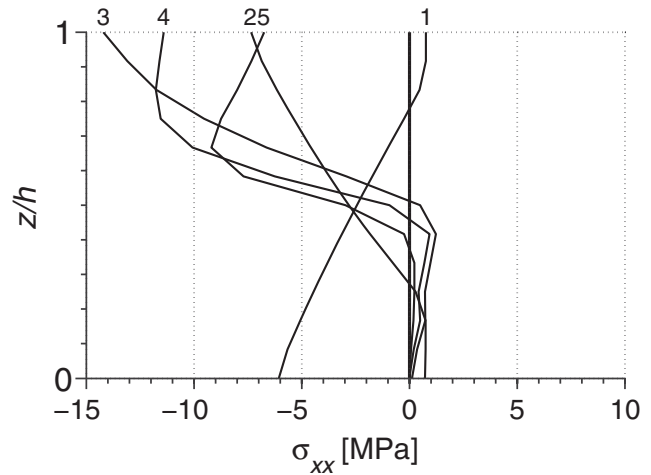

Fig. 8. Evolution of stress at midsection along the height: (1) prestressing stage; (2) intermediate service load stage; (3) peak load in compression; $(4,5)$ softening in compression after peak load

Table 3. Comparison of Critical Loads $P_{\text {ult }}$

\begin{tabular}{lccccccc}
\hline & \multicolumn{2}{c}{ Experiment } & & \multicolumn{2}{c}{ Strain compatibility } & & \multicolumn{2}{c}{ Simulations } \\
\cline { 2 - 3 } \cline { 7 - 8 } \cline { 7 - 8 } Beam & $P_{\text {ult }}(\mathrm{kN})$ & & $P_{\text {ult }}(\mathrm{kN})$ & $f_{p s}(\mathrm{MPa})$ & & $P_{\text {ult }}(\mathrm{kN})$ & $f_{p s}(\mathrm{MPa})$ \\
\hline $\mathrm{B}-7$ & 77.9 & & 78.03 & $1,442.3$ & & 79.9 & $1,501.9$ \\
$\mathrm{~B}-8$ & 71.1 & & 54.52 & 1,152 & & 69.3 & $1,386.6$ \\
$\mathrm{~B}-13$ & 50.9 & & 50.62 & $1,530.8$ & & 47.5 & $1,171.8$ \\
$\mathrm{~B}-25$ & 53.15 & & 47.83 & $1,404.2$ & & 52.9 & $1,495.0$ \\
$\mathrm{~B}-26$ & 41.2 & & 35.82 & $1,230.7$ & & 41.6 & $1,430.7$ \\
B-27 & 75.2 & 73.87 & $1,384.5$ & & 76.9 & $1,336.0$ \\
\hline
\end{tabular}

The load-deflection curves for the geometrically scaled beams are shown in Figs. 10(a) and 11(a). Beams B-8 and B-26 were chosen as representative of the beams relevant to compression crushing failure. Using the computed values of the peak loads (giving $M_{u}$ ) and of the steel stress $f_{p s}$ at the peak load for various beam sizes, one can then use Eqs. (1) and (2) to calculate for each beam depth $a$ of the equivalent rectangular stress block and the nominal strength $\sigma_{N}$. The resulting values of the ratio $\sigma_{N} / f_{c}^{\prime}$ at failure are plotted in Figs. 10(b) and 11(b).

At the peak load, the vertical profile of longitudinal normal stress averaged over thickness $b$ is plotted against the normalized beam depth $\eta=z / h$ for each of the four sizes; see Figs. 10(c) and 11(c). As can be seen, the compression zone has at peak load entered the strain-softening range, but barely so (which is why the size effect is only mild).
According to the design codes (ACI Committee 318 2008; fib 2010), the values of nominal strength $\sigma_{N}$, plotted in Figs. 10(b) and 11(b), should be independent of the beam size. But they are not, which is an evidence of size effect.

For the scaled beams shown in Fig. 10, the increase of size in the ratio of $1: 4$ causes $\sigma_{N}$ to decrease by about $7 \%$, and for the scaled beams shown in Fig. 11, the size increase in the same ratio causes $\sigma_{N}$ to decrease by about $8 \%$. These are not strong size effects, but neither are they negligible. However, the increase of the scaling ratio to $1: 8$ causes a decrease in $\sigma_{N}$ of about $30 \%$ for the beams shown in Fig. 10 and about $35 \%$ for the beams shown in Fig. 11.

The fact that, even for the large beams, Figs. 10(c) and 11(c) show only a small reduction of stress below the stress peak helps to explain why only a moderate size effect is found for the beams of the ratio 1:4. A significant reduction of strength below the strength limit is obtained at peak load only for much larger beams, with the scaling ratio of 1:8.

The ACI design code (ACI Committee 318 2008) specifies that $\sigma_{N} / f_{c}^{\prime}=0.85$. This limit is shown in Figs. 10(b) and 11(b), respectively. Because of a significant hidden safety margin, the size effect in the smaller size range (1:4) does not endanger structural safety. Nevertheless, the safety margin of the smallest beams is significantly greater than it is for the large beams. In other words, compared to the large beams, the small ones are more overdesigned for flexure and thus less economical, according to the current design codes, which neglect the size effect.

In theory, the data in Figs. 10(c) and 11(c) should follow the approximate size effect law of Type 2 in Bažant (1984), which reads as follows (Bažant and Planas 1997; Bažant 2005)

$$
\sigma_{N}=B f_{t}^{\prime}\left(1+d / d_{0}\right)^{-1 / 2}
$$

where $B=$ geometry constant and $d_{0}=$ transitional size. The optimum fits of Eq. (4) are shown by the solid curves in Figs. 10(b) and 11(b). The values of $d_{0}$ and of the coefficients of variation (COV), $\omega$, of regression errors (RMS error divided by data mean) are indicated in each figure.

Based on the optimal values of $d_{0}$, the data from Figs. 10(b) and 11(b) are replotted in one diagram in Fig. 12, as a function of the dimensionless size $d / d_{0}$. The COV of errors of the optimal fit in Fig. 12 is $1.8 \%$. The optimal fit curve would dip below 0.85 only for very large sizes, for which code specifications would not provide the required safety margin. Evidently, the sizes for which this happens are encountered only with very large structures, particularly large bridges. But those structures would have a reinforcing mesh in the compression zone, a case that would require a

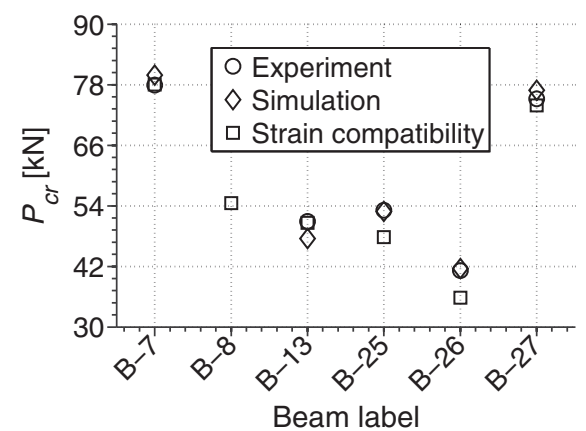

(a)

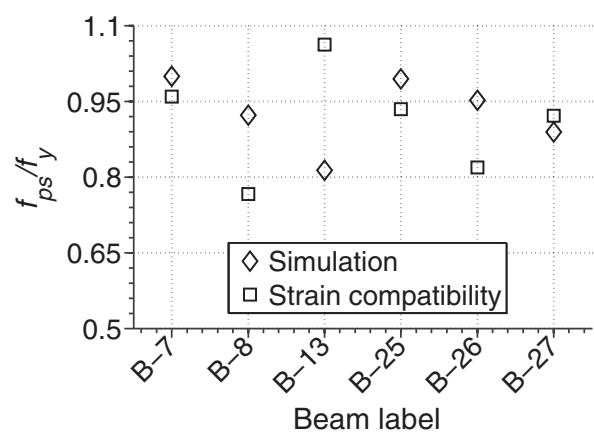

(b)

Fig. 9. (a) Peak load for Billet beams from the experiment, simulations, and strain compatibility approach; (b) stress in prestressing strand at the peak load 


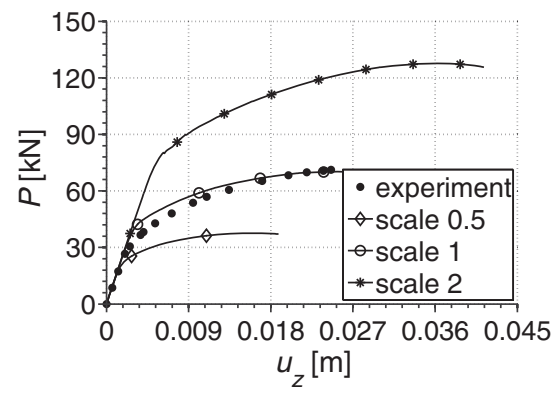

(a)

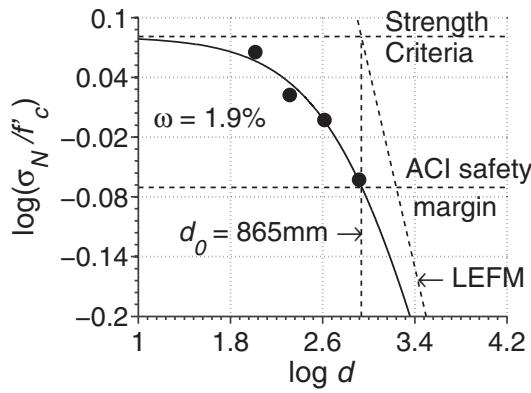

(b)

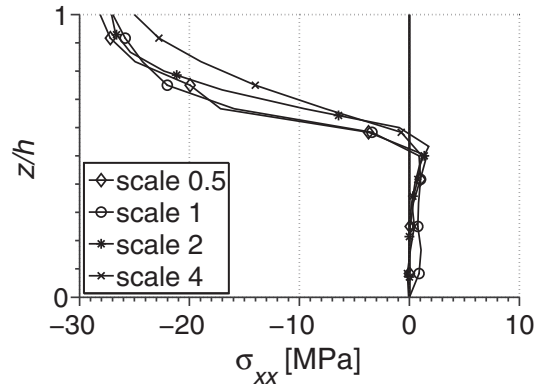

(c)

Fig. 10. Beam B-8: (a) geometric scaling; (b) size effect plot of nominal strength; (c) $\sigma_{x x}$ versus $z / h$ at peak load on surface of symmetry

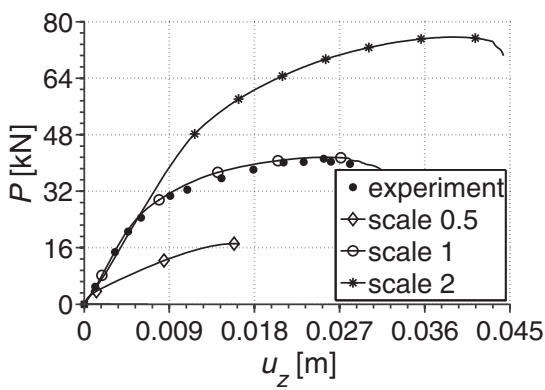

(a)

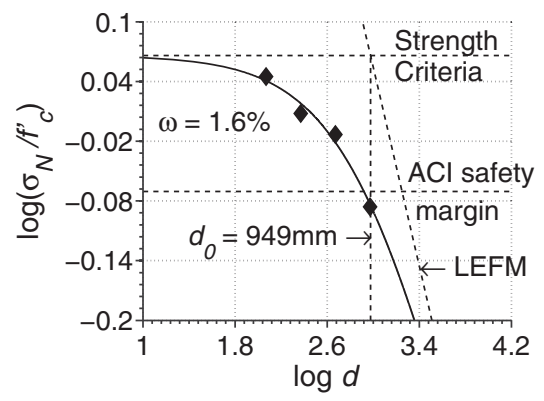

(b)

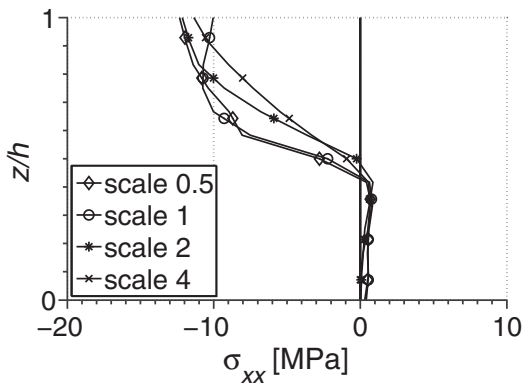

(c)

Fig. 11. Beam B-26: (a) geometric scaling; (b) size effect plot of nominal strength; (c) $\sigma_{x x}$ versus $z / h$ at peak load on surface of symmetry

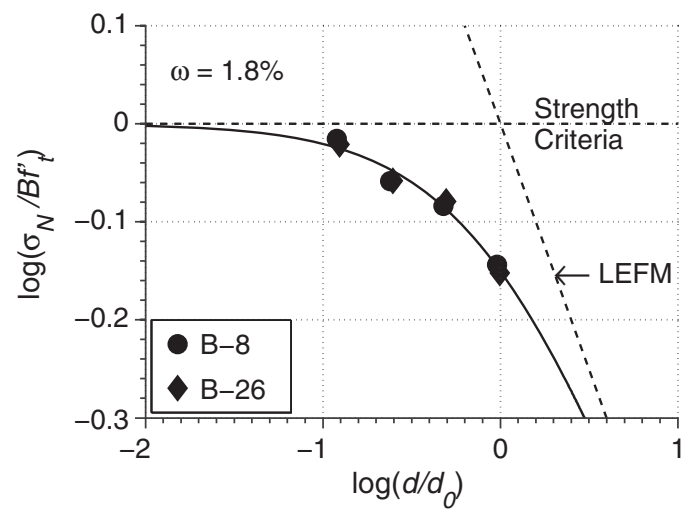

Fig. 12. Size effect plot of nominal strength

different analysis. Another study would be needed to explore that issue.

Is there any cause for alarm? For the smaller size range, which is the normal size range, the answer is no. In fact, the reduction of safety margin due to the size effect is compensated by various kinds of covert safety margins in the current code, as demonstrated in detail in Bažant and Frangopol (2002). For example, the code specifies a load factor of 1.4 for the selfweight acting alone, and 1.2 for load combinations. However, the error in selfweight cannot be larger than about 3\%. This means that larger beams, in which the selfweight is a much greater proportion of the total load, get penalized compared to small ones. This actually provides a hidden protection against a mild size effect such as the present one. However, if a more rational safety structure is introduced into the code, than a correction for the presently shown size effect should be implemented.

\section{Conclusions}

1. Within the size range investigated here, the flexural failure of geometrically scaled prestressed beams failing due to compression softening of concrete exhibits a size effect.

2. For the normal size range considered here, this size effect need not be implemented in the design code because the reverse size effect due to excessive selfweight load factor required by the code indirectly compensates for it.

3. The stress profiles across the compression damage zone exhibit at peak load only mild softening (i.e., only a mild stress reduction from the strength limit). This is one explanation why the size effect is only mild within the size range studied in this paper.

4. The other explanation is that the compression crushing (or softening) zone occupies a large portion of the beam.

5. Uniform safety margins, which are desired for economy and efficiency of design, could be achieved by applying a size effect correction factor to the stress in the rectangular compressive stress block used in beam-type strength analysis.

6. Based on an amply validated theory, whenever a structure fails by progressive softening damage, there is a transitional size effect bridging plastic limit analysis with no size effect and linear elastic fracture mechanics (LEFM) with the maximum possible size effect. Thus, prior to this study, the only question was whether the transition from the mild to strong size effect occurs within the practical size range or beyond it. The latter is what is indicated by this study.

7. A simple extrapolation to much deeper beams could be obtained by fitting Bažant's type 2 size effect law to the combined size effect data from finite element analysis. However, the extrapolation based on the present data alone is uncertain since the data fitted have a very high scatter. Besides, new experiments with larger beams would be needed to confirm or disprove this theoretical inference. 


\section{Acknowledgments}

Financial support from the U.S. Department of Transportation, provided through Grant 20778 from the Infrastructure Technology Institute of Northwestern University, as well as supplementary support for theoretical considerations provided through NSF Grant CMMI-1129449 to Northwestern University, is gratefully appreciated.

\section{References}

ACI Committee 318. (2008). "Building code requirements for structural concrete (ACI 318-05) and commentary (ACI 318-05)." Rep., American Concrete Institute (ACI), Farmington Hills, MI.

Barnard, P. (1965). "The collapse of reinforced concrete beams." ACI Special Publication, 12, 501-520.

Barnard, P., and Johnson, R. (1965). "Plastic behavior of continuous composite beams." ICE Proc., 32(2), 180-197.

Bažant, Z. (1967). "L'instabilité d'un milieu continu et la resistence en compression." Bull. RILEM, 35, 99-112.

Bažant, Z. (1984). "Size effect in blunt fracture: Concrete, rock, metal." J. Eng. Mech., 10.1061/(ASCE)0733-9399(1984)110:4(518), 518-535.

Bažant, Z. (2003a). "Asymptotic matching analysis of scaling of structural failure due to softening hinges. I: Theory." J. Eng. Mech., 10.1061/ (ASCE)0733-9399(2003)129:6(641), 641-650.

Bažant, Z. (2003b). "Asymptotic matching analysis of scaling of structural failure due to softening hinges. II: Implications." J. Eng. Mech., 10.1061/(ASCE)0733-9399(2003)129:6(651), 651-654.

Bažant, Z. (2005). Scaling of structural strength, Elsevier/ButterworthHeinemann, Oxford.

Bažant, Z., and Cedolin, L. (1991). Stability of structures. Elastic, inelastic, fracture, and damage theories, Oxford University Press, New York.

Bažant, Z., and Frangopol, D. (2002). "Size effect hidden in excessive dead load factor." J. Struct. Eng., 10.1061/(ASCE)0733-9445(2002) 128:1(80), 80-86.

Bažant, Z., and Kwon, Y. (1994). "Failure of slender and stocky reinforced concrete columns: Tests of size effect.” Mater. Struct., 27(2), 79-90.
Bažant, Z., and Planas, J. (1997). Fracture and size effect in concrete and other quasi-brittle materials. CRC Press, Boca Raton, FL.

Bažant, Z., and Xiang, Y. (1994). "Compressive failure of quaisbrittle materials and size effect." Damage Mech. Compos., 185, 143-148.

Bažant, Z., and Xiang, Y. (1997). "Size effect in compression fracture: Splitting crack band propagation." J. Eng. Mech., 10.1061/(ASCE) 0733-9399(1997)123:2(162), 162-172.

Billet, D. (1953). "Study of prestressed concrete beams failing in flexure." M.S. thesis, Univ. of Illinois, Urbana, IL.

Červenka, V., and Jendele, L. (2008). ATENA Program DocumentationPart 1: Theory. Cervenka Consulting, 〈http://www.cervenka.cz〉.

Feldman, A. (1954). "Bonded and unbonded prestressed concrete beams failing in flexure." M.S. thesis, Univ. of Illinois, Urbana, IL.

Grassl, P., and Jirásek, M. (2006). "Damage-plastic model for concrete failure." Int. J. Solids Struct., 43(22-23), 7166-7196.

Hillerborg, A. (1990). "Fracture mechanics concepts applied to moment capacity and rotational capacity of reinforced concrete beams." Eng. Frac. Mech., 35(1-3), 233-240.

Janney, J., Hogenstad, E., and McHenry, D. (1956). "Ultimate flexural strength of prestressed and conventionally reinforced concrete beams." JACI, 52, 601-620.

International Federation for Structural Concrete (fib). (2010). "Model code for concrete structures 2010." Ernst \& Sohn Publishing House, Berlin, Germany.

Nawy, E. (2006). Prestressed concrete, 5th Ed., Pearson-Prentice Hall, Upper Saddle River, NJ.

Nilson, A. (1987). Design of prestressed concrete, Wiley, New York.

Patzák, B., and Bittnar, Z. (2001). "Design of object oriented finite element code." Adv. Eng. Software, 32(10-11), 759-767.

Raju, N., Basavarajaiah, B., and Kutty, E. (1973). "Flexural behavior of concrete beams reinforced with limited prestress." Build. Sci., 8, $179-185$.

Tan, K., and Mansur, M. (1992). "Partial prestressing in concrete corbels and deep beams." ACI Struct. J., 89(3), 251-262.

van Mier, J. (1984). "Strain-softening of concrete under multiaxial conditions," Ph.D. thesis, Eindhoven Univ. of Technology, Eindhoven, The Netherlands.

Warwaruk, J. (1957). "Strength in flexure of bonded and unbonded prestressed concrete beams." M.S. thesis, Univ. of Illinois, Urbana, IL. 